\title{
Antioxidant Activity, Total Phenolic Content and Total Flavonoid Content of Water and Methanol Extracts of Phyllanthus species from Malaysia
}

\author{
Siti Nur Dalila Mohd Zain, Wan Adnan Wan Omar*
}

\section{Siti Nur Dalila Mohd Zain, Wan Adnan Wan Omar}

Advanced Medical and Dental Institute, Universiti Sains Malaysia, 13200 Kepala Batas, Penang, MALAYSIA.

\section{Correspondence}

\section{Dr. Wan Adnan Wan Omar}

Advanced Medical and Dental Institute Universiti Sains Malaysia, 13200 Kepala Batas, Penang, MALAYSIA.

Phone no : +6-04-562 2570

E-mail:wanadnan@usm.my

\section{History}

- Submission Date: 09-01-2018.

- Review completed: 14-02-2018;

- Accepted Date: 05-03-2018.

DOI : 10.5530/pj.2018.4.111

Article Available online

http://www.phcogj.com/v10/i4

\section{Copyright}

(c) 2018 Phcog.Net. This is an openaccess article distributed under the terms of the Creative Commons Attribution 4.0 International license.

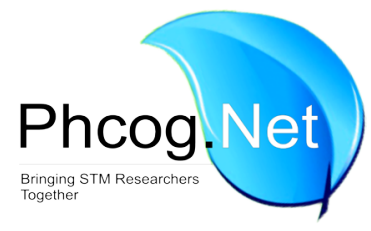

\begin{abstract}
Aims: The effects of 2 types of solvents, water and methanol were investigated to determine the presence of antioxidant activity, total phenolic content (TPC) and total flavonoid content (TFC) from three Phyllanthus species namely, Phyllanthus urinaria, Phyllanthus niruri andPhyllanthus debilis. Material and Methods: The antioxidant activities were measured using 2,2-diphenyl-1-picrylhydrazyl (DPPH) and 2,2'-azino-bis(3-ethylbenzothiazoline-6-sulphonic acid) (ABTS) assays. The chemical contents of the Phyllanthus sp. were presented as total phenolic content (TPC) and total flavonoid content (TFC). Statistical analysis: All statistical analysis was conducted using SPSS for Windows, Version 22. All data were presented as mean \pm standard deviation. Results: Our result showed that $P$. urinaria showed higher TPC, followed by $P$. debilis and $P$. niruri for both methanol and water extracts. Similarly, $P$. urinaria showed higher TFC than $P$. debilis and $P$. niruri. The antioxidant activity by using 2,2-diphenyl1-picrylhydrazyl (DPPH) assay showed $\mathrm{EC}_{50}$ of samples ranged from 15.8 to $29.3 \mu \mathrm{g} / \mathrm{mL}$ for methanol extract and 33.5 to $73.0 \mathrm{\mu g} / \mathrm{mL}$ for water extract. The 2,2'-azino-bis(3-ethylbenzothiazoline-6-sulphonic acid) (ABTS) assay showed $\mathrm{EC}_{50}$ ranged from 11.2 to $26.0 \mu \mathrm{g} / \mathrm{mL}$ for methanol extract and 13.5 to $37.4 \mu \mathrm{g} / \mathrm{mL}$ for water extract. Conclusion: Methanol extract showed higher TPC, TFC value and lower $\mathrm{EC}_{50}$ values for antioxidant activities when compared to water extract. In both methanol and water extracts, P. urinaria had higher TPC and TFC value and lower $\mathrm{EC}_{50}$ for both DPPH and ABTS assay followed by P. debilis and P. niruri.

Key words: Phyllanthus, Phenolic, Flavonoid, DPPH, ABTS.

Key Messages: This paper compared water and methanol extracts between Phyllanthus species in which there is lack of publication available on the effect of different solvents (water and methanol) on the physicochemical profiles (antioxidant, total phenolic and total flavonoid contents) between the species. Our study adds further data information of Phyllanthus debilis, in which this species was not well-researched. We found out that Phyllanthus urinaria, either water or methanol extract, gave better physicochemical profiles compared with $P$. debilis and $P$. niruri. Methanolic extract of $P$. urinaria showed better physicochemical profiles compared with water extract and its biological activity should be further studied.
\end{abstract}

\section{INTRODUCTION}

Pokok 'dukung anak' is the local name in Malaysia for a few species of herbaceous Phyllanthus plants. ${ }^{1}$ They are known as 'dukung anak', which means 'to carry a child', referring to the fruits at the bottom of each leaf petiole. ${ }^{2}$ It originated from India, but can be found in the tropical region worldwide. ${ }^{3}$ Recently, the species have become of research interest due to their use in traditional medicine and were shown to have strong medicinal properties. ${ }^{4}$

Phyllanthus species such as Phyllanthus acidus, Phyllanthus debilis, Phyllanthus pulcher, Phyllanthus reticulatus, Phyllanthus urinaria, Phyllanthus niruri and Phyllanthus myrtifolius are traditionally used for treatment of several diseases in many tropical countries. Whole plant or parts of it were used for the treatment of kidney stones, intestinal infections, diabetes, hepatitis B and neonatal jaundice. ${ }^{5,6}$ There are 3 common Phyllanthus species that were traditionally used for treatment in Malaysia. The species are Phyllanthus niruri, Phyllanthus debilis and Phyllanthus urinaria.

P. niruri is the most common Phyllanthus species used as medicine in most of tropical countries. ${ }^{7}$ It has diverse medicinal qualities where it has been used for treatment ranging from kidney problems, diarrhoea, fever, diabetes, colic, anti-lipid and analgesic. ${ }^{8,9}$ The analysis of its extracts showed many bioactive compounds, which has diverse pharmacological and therapeutic potentials such as lignans,

Cite this article: Zain SNDM, Omar WAW. Antioxidant Activity, Total Phenolic Content and Total Flavonoid Content of Water and Methanol Extracts of Phyllanthus species from Malaysia. Pharmacog J. 2018;10(4):677-81. 
phyllanthin, hypophyllanthin, tannins, triterpenes, phenyl propanoids, ricinolic acid, niruriside and phyltetralin. ${ }^{5,10-14}$ Bioactive compounds such as lignans and terpenes were shown to have an excellent hepatoprotective effects, anti-cancer and anti-microbial properties. ${ }^{11}$ Other active compounds, niruriside has antiviral activity that can inhibit the replication of HIV virus. ${ }^{15}$

P. urinaria has similar uses as $P$. niruri in traditional practises. It is commonly used for treatment of fever, improving eyesight, urinary problems, and liver diseases and to detoxify poison from the body. ${ }^{9,8}$ In China, P. urinaria was mainly used for treatment of cancer. ${ }^{16,17}$ Some compounds such as 7'-hydroxy-3',4',5,9,9'-pentamethoxy-3,4-methylene dioxy lignan isolated from P.urinaria extracts was shown to exhibit anticancer activity. ${ }^{18}$ Other bioactive compounds found in the P. urinaria extract such as coumarin, ellagitannin and sterol can act as antioxidant, antiviral and anti-inflammatory. ${ }^{19}$

P. debilis, which is a less known Phyllanthus species, is usually used as substitute to other popular Phyllanthus species such as P. amarus. ${ }^{8}$ P. debilis is commonly used for treatment such as jaundice, diarrhea, ulcers, sores, ringworms and scabies. ${ }^{20}$ Although known as a substitute for P. amarus, $P$. debilis has been found to have a better hepatoprotective activity than P. amarus. $^{21}$ It is also showing a strong anti-inflammatory ${ }^{22}$ and antihyperglycemic properties. ${ }^{20}$ Bioactive compound found in $P$. debilis such as debelalactone acts as antihepatotoxic whereas phytoesterols such as $\beta$-sitosterol act as analgesic and anti-inflammatory. ${ }^{19}$

This study was aimed to compare physicochemical profiles (TPC, TFC and antioxidant activity) of methanol and water extracts in 3 common Malaysian Phyllanthus species.

\section{MATERIALS AND METHODS}

\section{Herbal specimen}

Three Phyllanthus species were collected from local collection at Tasek Gelugor, Penang, Malaysia. These species were identified by a botanist, Dr. Rahmad Zakaria from the School of Biological Sciences, Universiti Sains Malaysia. The voucher specimens (Phyllanthus debilis: 11623, Phyllanthus niruri: 11624 and Phyllanthus urinaria: 11625) were deposited at the USM herbarium.

\section{Sample extraction \\ Water/methanol extraction}

The sample extraction method was done according to Huang et al., $(2008)^{23}$ with slight modification. Briefly, the sample was dried in the oven of $50^{\circ} \mathrm{C}$ for 3 days. Dried samples were ground and prepared in powder form. Five gram of sample was extracted with $100 \mathrm{~mL}$ of deionized water or methanol (Fisher Chemical) in ultrasonic bath (Power Sonic 405) for $20 \mathrm{~min}$ and then filtered. The process was repeated twice with the remaining residual extract. The extracts were dried using freeze dryer for water extract and rotary evaporator (Buchi Rotary Evaporator RII) for methanol extract. Dried extracts were stored at $-20^{\circ} \mathrm{C}$ prior to use.

\section{Total phenolic content}

Total phenolic concentration in the extracts was determined based on the method of Sahu and Saxena, (2013). ${ }^{24}$ with slight modification. Briefly, $2 \mathrm{mg} / \mathrm{mL}$ of sample was diluted in methanol or ultrapure water. Fifty microliters of Folin-Ciocalteu's reagent (50\% v/v) (Merck) was then added to $10 \mu \mathrm{L}$ of sample solution and incubated for $5 \mathrm{~min}$ incubation at room temperature. Forty microliters of $20 \%$ (w/v) sodium carbonate (Bio-basic) was added to the mixture which was then incubated for $30 \mathrm{~min}$. The absorbance was read at $765 \mathrm{~nm}$ using microplate reader (FLUOstar omega). The total phenolic was expressed in gallic acid equivalent (GAE) per g dry weight (DW) of extract (mg GAE/g DW).
The standard curve of gallic acid was constructed using seven serial concentrations ( 1.563 to $50 \mu \mathrm{g} / \mathrm{mL}$ ). All samples were assays in triplicate. Water and methanol were used as negative control.

\section{Total flavonoid content}

Total flavonoid content (TFC) of Phyllanthus samples was determined based on the method of Sahu and Saxena, (2013), ${ }^{24}$ with some modifications. Briefly, sample solution was prepared using $2 \mathrm{mg} / \mathrm{ml}$ of extract, diluted using methanol or ultrapure water. Hundred $\mu \mathrm{L}$ of sample solution $(2 \mathrm{mg} / \mathrm{mL}$ ) was then mixed with $100 \mu \mathrm{L}$ of $2 \%$ aluminium chloride $\left(\mathrm{AlCl}_{3}\right)(\mathrm{Merck})$ in 96 microwell plate. A flavonoid-aluminium complex was formed after $10 \mathrm{~min}$ of incubation time at $25^{\circ} \mathrm{C}$. The formation of the complex was measured at $415 \mathrm{~nm}$ using microplate reader (FLUOstar omega). Total flavonoid content was measured as quercetin equivalent (QE) per g dry weight (DW) of extract (mg QE/g DW). The standard curve of quercetin was constructed using seven serial concentrations $(1.563$ to $50 \mu \mathrm{g} / \mathrm{mL})$. All assays were carried out in triplicate. Water and methanol were used as blank and negative control.

\section{Antioxidant activity: DPPH free radical scavenging assay}

The antioxidant activity was measured based on the free radical scavenging activity of the Phyllanthus extracts against the stable 2, 2-diphenyl-1-picrylhydrazil (DPPH) free radical. ${ }^{25} \mathrm{~A}$ total $250 \mu \mathrm{L}$ of a reaction mixture was prepared in 96 microwell plates. The reaction mixture consisted of $50 \mu \mathrm{L}$ of extracts and $200 \mu \mathrm{L}$ of $0.2 \mathrm{mM} \mathrm{DPPH}$ (Sigma-Aldrich). The solution was incubated at room temperature for $30 \mathrm{~min}$ before measuring the absorbance value at $517 \mathrm{~nm}$ using microplate reader (FLUOstar omega). Different concentrations of the extracts were measured and $\mathrm{EC}_{50}$ concentration (concentration required to inhibit 50\% of DPPH radicals) was determined. All assays were carried out in triplicate. Water and methanol were used as negative controls. Obtained absorbance value was converted into the percentage of radical scavenging activity using the following equation:

$$
\text { Radical scavenging activity }(\%)=100-\frac{\mathrm{AS}}{\mathrm{AC}} \times 100
$$

Where AS refers to: absorbance of the sample;

AC: absorbance of the negative control (methanol/ water).

\section{Antioxidant activity: ABTS scavenging activity}

Antioxidant activity was also measured using ABTS 2,2'-azino-bis(3ethylbenzothiazoline-6-sulphonic acid) (Roche Diagnostic). The ABTS radical cation $\mathrm{ABTS}^{+}$solution was prepared through the reaction of $7 \mathrm{mM}$ ABTS with $2.45 \mathrm{mM}$ potassium persulphate (Sigma-Aldrich). The mixture was incubated at room temperature for 16 hours in the dark. The $\mathrm{ABTS}^{+}$solution was then diluted with $99 \%$ ethanol (R\&M Chemical) to obtain an absorbance of $0.7 \pm 0.02$ at $734 \mathrm{~nm}$. A total of $200 \mu \mathrm{l}$ of reaction mixture was prepared in 96 well plates.

The reaction mixture consists of $10 \mu \mathrm{L}$ of extracts and $190 \mu \mathrm{L}$ of diluted $\mathrm{ABTS}^{+}$. The mixture was incubated for $6 \mathrm{~min}$ at the room temperature before measuring the absorbance value at $734 \mathrm{~nm}$ using microplate reader (Powerwave XS bio-tek). Different concentrations of the extracts were measured and $\mathrm{EC}_{50}$ concentration (concentration required to inhibit $50 \%$ of ABTS) was determined. All assays were carried out in triplicate. Water and methanol were used as negative controls.

Obtained absorbance value was converted into the percentage of radical scavenging activity using the following equation: 
Radical scavenging activity $(\%)=100-\frac{\mathrm{AS}}{\mathrm{AC}} \times 100$

Where AS: absorbance of the sample;

AC: absorbance of the negative control (methanol/ water).

\section{Statistical analysis}

All statistical analysis was conducted using SPSS for Windows, Version 22. All data were presented as mean \pm standard deviation.

\section{RESULTS AND DISCUSSION}

The total phenolic content of the whole plant of $P$. niruri, $P$. urinaria and $P$. debilis was presented in Table 1 . For methanol extract, $P$. urinaria had a higher total phenolic content (308.71 $\pm 0.04 \mathrm{mg} \mathrm{GAE} / \mathrm{g} \mathrm{DW})$ followed by P. debilis (197.09 $\pm 0.03 \mathrm{mg} \mathrm{GAE} / \mathrm{g} \mathrm{DW})$ and P. niruri $(159.13 \pm 0.02 \mathrm{mg}$ GAE/g DW). Similarly, for water extract, $P$. urinaria showed the highest phenolic content $(219.83 \pm 0.01 \mathrm{mg} \mathrm{GAE} / \mathrm{g}$ DW), followed by $P$. debilis (172.09 $\pm 0.01 \mathrm{mg} \mathrm{GAE} / \mathrm{g} \mathrm{DW})$ and P. niruri $(107.09 \pm 0.01 \mathrm{mg} \mathrm{GAE} / \mathrm{g} \mathrm{DW})$.

The plant phenolic compounds constitute one of the major groups of compounds acting as primary antioxidants or free radical terminators. This is due to their redox properties, which play an important role in adsorbing and neutralising free radicals, quenching singlet or triplet oxygen and decomposing peroxides. $^{26}$ Our results showed that the methanol extract of P. urinaria exhibited the highest TPC, followed by $P$. debilis and $P$. niruri. Similar observation was previously reported ${ }^{27}$ which found that $P$. urinaria had higher TPC content compared to $P$. debilis and P. amarus. However, TPC for methanol extract of $P$. urinaria in our study was higher than TPC content in methanol extract of $P$. urinaria found in Eldeen et al. (2011) ${ }^{27}$ study $(308.0 \pm 0.01$ mg GAE/g DW vs $205.0 \pm 21.3 \mathrm{mg} \mathrm{GAE} / \mathrm{g}$ DW). The water extract of $P$. urinaria showed lower TPC content when being compared to methanol extract. When being compared with the study by Cheah and Radu, (2011), ${ }^{28}$ the water extracts of $P$. urinaria and P. niruri from our samples were showing higher TPC values $(219.83 \pm 0.01 \mathrm{mg}$ GAE/g DW vs $41.19 \pm 0.689 \mathrm{mg} \mathrm{GAE} / \mathrm{g}$ DW for $P$. urinaria and $107.09 \pm 0.01 \mathrm{mg}$ GAE/g DW vs $55.38 \pm 0.496 \mathrm{mg}$ GAE/g DW for $P$. niruri). The higher TPC value found in our samples may be due to different drying process in which our samples were dried at $50^{\circ} \mathrm{C}$ whereas in Eldeen et al., (2011), ${ }^{27}$ their samples were dried in an oven at $60^{\circ} \mathrm{C}$. This may suggest that the drying temperature of more than $50^{\circ} \mathrm{C}$ may not be suitable for extracting the phenolic compounds. Exposing the samples to direct sunlight or relevant high temperature may cause some phenolic compounds to degrade rapidly. ${ }^{29}$

Table 1: Total phenolic content of three Phyllanthus species in mg GAE/g DW.

\begin{tabular}{ccc}
\hline Species & Methanol extract & Water extract \\
\hline P. niruri & $159.13 \pm 0.02$ & $107.09 \pm 0.01$ \\
P. urinaria & $308.71 \pm 0.04$ & $219.83 \pm 0.01$ \\
P. debilis & $197.09 \pm 0.03$ & $172.09 \pm 0.01$ \\
\hline
\end{tabular}

Values are mean \pm standard deviation $(\mathrm{n}=3)$

Table 2: Total flavonoid content of three Phyllanthus species in mg QE/g DW.

\begin{tabular}{ccc}
\hline Species & Methanol extract & Water extract \\
\hline P. niruri & $22.08 \pm 0.04$ & $7.07 \pm 0.01$ \\
P. urinaria & $35.86 \pm 0.04$ & $17.27 \pm 0.01$ \\
P. debilis & $25.64 \pm 0.16$ & $8.19 \pm 0.01$ \\
\hline
\end{tabular}

Values are mean \pm standard deviation $(\mathrm{n}=3)$
The total flavonoid content of three Phyllanthus species is presented in Table 2. For methanol extract, $P$. urinaria had a higher total flavonoid content (35.86 $\pm 0.04 \mathrm{mg} \mathrm{QE} / \mathrm{g}$ DW) followed by P. debilis $(25.64 \pm 0.16 \mathrm{mg} \mathrm{QE} / \mathrm{g}$ $\mathrm{DW})$ and $P$. niruri $(22.08 \pm 0.04 \mathrm{mg} \mathrm{QE} / \mathrm{g} \mathrm{DW})$. For water extracts, $P$. urinaria shows the highest total flavonoid content $(17.27 \pm 0.01 \mathrm{mg}$ QE/g DW), followed by P. debilis (8.19 $\pm 0.01 \mathrm{mg} \mathrm{QE} / \mathrm{g} \mathrm{DW})$ and P. niruri $(7.07 \pm 0.01 \mathrm{mg} \mathrm{QE} / \mathrm{g} \mathrm{DW})$.

Flavonoids are commonly found in natural products and one of the most important natural phenolics. ${ }^{7}$ For methanol and water extracts, $P$. urinaria exhibited the highest TFC compared to $P$. debilis and $P$. niruri. Methanol extracts showed higher TFC value when being compared to water extract. Our result was in agreement with Kumaran and Karunakaran (2007), ${ }^{7}$ which showed that $P$. urinaria exhibited higher TFC value compared with other Phyllanthus species such as P. debilis and P. amarus.

\section{Antioxidant assay}

Two assays which were 2,2-diphenyl-1-picrylhydrazyl(DPPH) freeradical scavenging activity and 2,2'-azino-bis(3-ethylbenzothiazoline-6-sulphonic acid) (ABTS) scavenging activity were used to evaluate antioxidant activity. Table 3 presents the $\mathrm{EC}_{50}$ values (concentration required to inhibit $50 \%$ of DPPH radicals) of three Phyllanthus species. Lower $\mathrm{EC}_{50}$ value indicates higher radical scavenging activity and higher antioxidant activity. The highest radical scavenging activity was shown by methanol extract of $P$. urinaria with $\mathrm{EC}_{50}$ of $15.8 \pm 0.01 \mu \mathrm{g} / \mathrm{mL}$. The radical scavenging activity of the methanol extracts decreased in the following order; P. urinaria $(15.8 \pm 0.01 \mu \mathrm{g} / \mathrm{mL})>P$. debilis $(26.3 \pm 0.01 \mu \mathrm{g} / \mathrm{mL})>$ P. niruri $(29.3 \pm 0.01 \mu \mathrm{g} / \mathrm{mL})$. For water extract, $P$. urinaria $(33.5 \pm 0.04$ $\mu \mathrm{g} / \mathrm{mL})>$ P. debilis $(45.0 \pm 0.02 \mu \mathrm{g} / \mathrm{mL})>$ P. niruri $(73.0 \pm 0.03 \mu \mathrm{g} / \mathrm{mL})$.

$\mathrm{DPPH}$ is a stable free radical and accepts an electron or hydrogen radical to become a stable diamagnetic molecule. ${ }^{30}$ The reduction capability of $\mathrm{DPPH}$ radical is determined by the decrease in absorbance at $517 \mathrm{~nm}$ induced by antioxidants. In general, methanol extracts of all Phyllanthus $s p$. showed lower $\mathrm{EC}_{50}$ values when compared with water extracts. In both methanol and water extracts, $P$. urinaria showed the highest DPPH scavenging activity, followed by $P$. debilis and P. niruri. A study ${ }^{27}$ also reported a similar finding where the DPPH inhibition activity of methanol extract of P. urinaria was found to be higher than other Phyllanthus spp. such as $P$. debilis.

Table 4 presents the $\mathrm{EC}_{50}$ values of ABTS inhibition of three Phyllanthus species. The highest radical scavenging activity of methanol extract was shown by methanol extract of $P$. urinaria with $\mathrm{EC}_{50}$ of $11.2 \pm 0.01 \mu \mathrm{g} / \mathrm{mL}$, followed by $P$. debIlis $(16.2 \pm 0.03 \mu \mathrm{g} / \mathrm{mL})$ and P. niruri $(26.0 \pm 0.02 \mu \mathrm{g} / \mathrm{mL})$. In water extract, $P$. urinaria also showed higher radical scavenging activity

Table 3: EC50 in $\mu \mathrm{g} / \mathrm{ml}$ of Phyllanthus species for DPPH radical scavenging activity.

\begin{tabular}{ccc}
\hline Species & Methanol extract & Water extract \\
\hline P. niruri & $29.3 \pm 0.01$ & $73.0 \pm 0.03$ \\
P. urinaria & $15.8 \pm 0.01$ & $33.5 \pm 0.04$ \\
P. debilis & $26.3 \pm 0.01$ & $45.0 \pm 0.02$ \\
\hline
\end{tabular}

Values are mean \pm standard deviation $(\mathrm{n}=3)$

Table 4: $\mathrm{EC}_{50}$ in $\mu \mathrm{g} / \mathrm{ml}$ of Phyllanthus species for ABTS scavenging activity.

\begin{tabular}{ccc}
\hline Species & Methanol extract & Water extract \\
\hline P. niruri & $26.0 \pm 0.02$ & $37.4 \pm 0.02$ \\
P. urinaria & $11.2 \pm 0.01$ & $13.5 \pm 0.05$ \\
P. debilis & $16.2 \pm 0.03$ & $23.0 \pm 0.01$ \\
\hline
\end{tabular}

Values are mean \pm standard deviation $(n=3)$ 
with $\mathrm{EC}_{50}$ of $13.5 \pm 0.05 \mu \mathrm{g} / \mathrm{mL}$, followed by $P$. debilis $(23.0 \pm 0.01 \mu \mathrm{g} / \mathrm{mL})$ and P. niruri $(37.4 \pm 0.02 \mu \mathrm{g} / \mathrm{mL})$.

For the antioxidant activity using ABTS scavenging activity, it was determined by the decolourisation of the ABTS by measuring the percentage of the reduction of absorbance at $734 \mathrm{~nm}$ and the results were presented as $\mathrm{EC}_{50}$ concentration. Similar to what was observed in antioxidant activity of DPPH assay, P. urinaria exhibited the lowest $\mathrm{EC}_{50}$, followed by $P$. debilis and P. niruri in both methanol and water extracts.

Our data showed that the chemical contents and antioxidant activity of the methanol extract was consistently higher compared to water extract. We believed that the difference between methanol and water extracts was due to the solvent polarity difference. Lim and Murtijaya (2007) $)^{29}$ had shown that methanol is better than water to degrade the cell wall, which results in greater amount of endocellular materials extracted. Furthermore, methanol is preferred than water to extract phenolic compounds in Phyllanthus species where major components, which are active hydrolysable tannins can be efficiently extracted using semi polar compounds. ${ }^{31}$ A study by Cheah and Radu, $(2011)^{28}$ also showed that methanol extract had a better TPC and DPPH activity when compared to water extract. Plant antioxidant activity however, also depends on other non-polyphenolic compound such as vitamins, minerals and carotenoids. These non-polyphenolic compounds may exert synergistic effect with TPC and TFC, which could further enhance the antioxidants activities.?

\section{CONCLUSION}

Phyllanthus species originated from Malaysia are high in antioxidant activities, total phenolic and flavonoid contents with possibilities of having high medicinal properties that can be potentially developed as medicine in future. Phyllanthus species especially $P$. urinaria showed higher amount of total phenolic and flavonoid contents and antioxidant activities when compared to $P$. debilis and P. niruri. Further studies are warranted for the isolation and identification of individual phenolic and flavonoid compounds and for better understanding of their biological mechanism.

\section{ACKNOWLEDGEMENT}

The authors gratefully acknowledge the financial support from Universiti Sains Malaysia short term research grant (grant number 304/ CIPPT/6312130)

\section{ABBREVIATIONS}

$\mathrm{EC}_{50}$ : effective concentration; $\boldsymbol{\mu g} / \mathrm{ml}$ : microgram per mililiter; HIV: Human Immunodeficiency Virus; ${ }^{\circ} \mathrm{C}$ : degree celcius; $\mathbf{m g} / \mathbf{m L}$ : milligram per mililiter; $\mathbf{v} / \mathbf{v}$ : volume per volume; $\mu \mathrm{L}$ : microliter; min: minutes; $\mathbf{n m}$ : nanometer; $\mathbf{m g} / \mathbf{g}$ DW: milligram per gram dry weight; $\mathbf{m M : ~ m i l i M o l a r . ~}$

\section{CONFLICT OF INTERESET}

Authors declare no conflict of interest.

\section{REFERENCES}

1. Mamat WZW, Yaacob M. 2015. Effect of planting density on growth and biomass yields of two dukung anak species, Phyllanthus debilis and Phyllanthus urinaria, grown on alluvial soil (Pengaruh populasi tanaman terhadap pertumbuhan dan hasil dua spesies dukung anak, Phyllanthus debilis dan Phyllanthus urinaria di tanah aluvium). Journal of Tropical Agriculture and Food Science. 2015;35:1-8.

2. Mediani A, Abas F, Khatib A, Tan CP, Ismail IS, Shaari K. Phytochemical and biological features of Phyllanthus niruri and Phyllanthus urinaria harvested at different growth stages revealed by $1 \mathrm{H}$ NMR-based metabolomics. Industrial Crops and Products. 2015;77:602-13

3. Sabir SM, Rocha JBT. Water-extractable phytochemicals from Phyllanthus niruri exhibit distinct in vitro antioxidant and in vivo hepatoprotective activity against paracetamol-induced liver damage in mice. Food Chemistry. 2008;111(4):845-51

4. Kalidass C, Mohan VR. in vitro rapid clonal propagation of Phyllanthus urinaria
Linn. (Euphorbiaceae): A medicinal plant. The Researcher. 2009;4:61-5.

5. Calixto JB, Santos AR, Filho VC, Yunes RA. A review of the plants of the genus Phyllanthus: their chemistry, pharmacology, and therapeutic potential. Medicinal research reviews. 1998;18(4):225-58.

6. Kumaran A, Karunakaran RJ. Anti-oxidant activity of polyphenols from Phyllanthus debilis Klein ex Willd. Journal of Natural Remedies. 2006;6(2):141-6.

7. Wong BY, Tan CP, Ho CW. Effect of solid-to-solvent ratio on phenolic content and antioxidant capacities of "Dukung Anak" (Phyllanthus niruri). International Food Research Journal. 2013;20(1):325-30.

8. Kumaran A, Karunakaran RJ. in vitro antioxidant activities of methanol extracts of five Phyllanthus species from India. LWT-Food Science and Technology. 2007;40(2):344-52.

9. Amin ZA, Abdulla MA, Ali HM, Alshawsh MA, Qadir SW. Assessment of in vitro antioxidant, antibacterial and immune activation potentials of aqueous and ethanol extracts of Phyllanthus niruri. Journal of the Science of Food and Agriculture. 2012;92(9):1874-7.

10. Rajeshkumar NV, Joy KL, Kuttan G, Ramsewak RS, Nair MG, Kuttan R. Antitumour and anticarcinogenic activity of Phyllanthus amarus extract. Journal of Ethnopharmacology. 2002;81(1):17-22

11. Bagalkotkar G, Sagineedu SR, Saad MS, Stanslas J. Phytochemicals from Phyllanthus niruri Linn. and their pharmacological properties: a review. Journal of pharmacy and pharmacology. 2006;58(12):1559-70.

12. Xiang-rong L, Wu Z, Wan-xing W. Chemical Components and Bioactivities of Phyllanthus niruri L. Natural Product Research and Development. 2007;19(5).

13. Van Dau N, Ha TTT. Chemical composition of Phyllanthus niruri L, Euphorbiaceae. TAP CHI DUOC HOC-SAIGON THEN HANOI. 2007;1:15

14. Narendra K, Swathi J, Sowjanya K, Satya A. Phyllanthus niruri: a review on its ethno botanical, phytochemical and pharmacological profile. Journal of Pharmacy Research. 2012;5(9):4681-91.

15. Qian-Cutrone J, Huang S, Trimble J, Li H, Lin PF, Alam M. Niruriside a new HIV REV/RRE binding inhibitor from Phyllanthus niruri. Journal of natural products. 1996;59(2):196-9

16. Huang ST, Pang JHS, Yang RC. Anti-cancer effects of Phyllanthus urinaria and relevant mechanisms. Chang Gung Medical Journal. 2010;33(5):477-87.

17. Tang YQ, Jaganath IB, Sekaran SD. Phyllanthus spp. induces selective growth inhibition of PC-3 and MeWo human cancer cells through modulation of cell cycle and induction of apoptosis. PLoS One. 2010;5(9):e12644.

18. Giridharan P, Somasundaram ST, Perumal K, Vishwakarma RA, Karthikeyan NP, Velmurugan $\mathrm{R}$, et al. Novel substituted methylenedioxy lignan suppresses proliferation of cancer cells by inhibiting telomerase and activation of c-myc and caspases leading to apoptosis. British journal of cancer. 2002;87(1):98-105.

19. Sarin B, Verma N, Martín JP, Mohanty A. An overview of important ethnomedicinal herbs of Phyllanthus species: present status and prospects. The Scientific World Journal. 2014

20. Wanniarachchi KK, Peiris LDC, Ratnasooriya WD. Antihyperglycemic and hypoglycemic activities of Phyllanthus debilis aqueous plant extract in mice. Pharmaceutical Biology. 2009;47(3):260-5.

21. Sane RT, Kuber WV, Chalissery MS, Menon S. Hepatoprotection by Phyllanthus amarus and Phyllanthus debilis in $\mathrm{CCl} 4$-induced liver dysfunction. Current Science. 1995;68(12):1243-6.

22. Chandrashekar KS, Joshi AB, Satyanarayana D, Pai P. Analgesic and Anti-inflammatory Activities of Phyllanthus debilis. Whole Plant. Pharmaceutical biology. 2005;43(7):586-8

23. Huang Z, Xiao S, Luo D, Chen B, Yao S. Simultaneous determination of sibutramine and $\mathrm{N}$-di-desmethylsibutramine in dietary supplements for weight control by HPLC-ESI-MS. Journal of chromatographic science. 2008;46(8):707-11.

24. Sahu R, Saxena J. Screening of total phenolic and flavonoid content in conventional and non-conventional species of Curcuma. Journal of Pharmacognosy and Phytochemistry. 2013;2(1).

25. Harish R. Shivanandappa T. Antioxidant activity and hepatoprotective potential of Phyllanthus niruri. Food chemistry. 2006;95(2):180-5.

26. Osawa TO. S. H. I. H. I. K. O. Novel natural antioxidants for utilization in food and biological systems. Postharvest biochemistry of plant food-materials in the tropics. 1994;241-51.

27. Eldeen IMS, Seow EM, Abdullah R, Sulaiman SF. in vitro antibacterial, antioxidant, total phenolic contents and anti-HIV-1 reverse transcriptase activities of extracts of seven Phyllanthus sp. South African Journal of Botany. 2011;77(1):75-9.

28. Cheah YK, Radu S. Bioprotective properties of three Malaysia Phyllanthus species: An investigation of the antioxidant and antimicrobial activities. International Food Research Journal. 2011;18(3):887-93.

29. Lim YY, Murtijaya J. Antioxidant properties of Phyllanthus amarus extracts as affected by different drying methods. LWT-Food Science and Technology. 2007;40(9):1664-9.

30. Soares JR, Dinis TC, Cunha AP, Almeida L. 1997. Antioxidant activities of some extracts of Thymus zygis. Free radical research. 1997;26(5):469-78.

31. Markom M, Hasan M, DaudWRW, Singh H, Jahim JM. Extraction of hydrolysable tannins from Phyllanthus niruri Linn.: Effects of solvents and extraction methods. Separation and Purification Technology. 2007;52(3):487-96. 
ABOUT AUTHORS

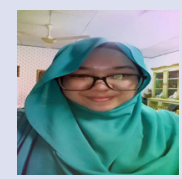

Siti Nur Dalila Mohd Zain: Obtained her Master's degree in Health Toxicology from Universiti Sains Malaysia, Penang, Malaysia. She has also completed her Bachelors in Science (Botany) from Universiti Sains Malaysia, Penang, Malaysia. She currently doing her PhD at the same university in the molecular study by studying the effect of herbal compounds on epigenetic regulation

\section{SUMMARY}

- P. urinaria showed highest TPC, followed by $P$. debilis and $P$. niruri for both methanol and water extracts.

- P. urinaria also showed highest TFC than the other species.

- The antioxidant activity by using DPPH assay and ABTS assay showed P. urinaria has lowest EC50 values than $P$. niruri and $P$. debilis

Cite this article: Zain SNDM, Omar WAW. Antioxidant Activity, Total Phenolic Content and Total Flavonoid Content of Water and Methanol Extracts of Phyllanthus species from Malaysia. Pharmacog J. 2018;10(4):677-81. 